
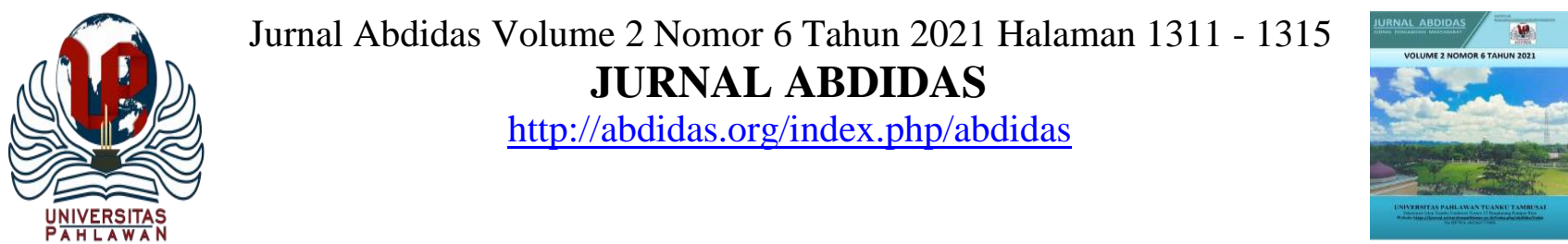

\title{
Membangun Nilai-nilai Demokrasi Melalui Pendidikan Kewarganegaraan di SMP Negeri 2 Limboto Kabupaten Gorontalo
}

\author{
Lucyane Djaafar $^{1 凶}$, Roni Lukum ${ }^{2}$, Zulfikar Adjie $^{3}$, Refandi Damopolii ${ }^{4}$, Sintia Wantu ${ }^{5}$, \\ Siti Ramiati Alim ${ }^{6}$ \\ PPKn, Fakultas Ilmu Sosial, Universitas Negeri Gorontalo, Indonesia ${ }^{1,2,3,4,5,6}$ \\ E-mail : lucyane.djaafar@gmail.com ${ }^{1}$ ronilukum@ung.ac.id ${ }^{2} \underline{z u l f i k a r a d j i e @ u n g . a c . i d ~}^{3}$ \\ refandidamopolii@gmail.com ${ }^{4}$ sintiawantu@gmail.com ${ }^{5}$ ramiatialim@gmail.com ${ }^{6}$
}

\begin{abstract}
Abstrak
Nilai demokrasi pada siswa merupakan perilaku toleransi, menghargai pertentangan pendapat dan mengetahui keberagaman di lingkungan sekolah. Kurangnya sikap dan prilaku nilai-nilai demokrasi pada siswa SMP N 2 Limboto yang disebabkan oleh beberapa faktor yaitu: (a) kurangnya perhatian dari lingkungan keluarga terhadap proses pembelajaran anak dirumah; (b) Sebagain besar lingkungan tempat tinggal anak berada di pinggiran Danau Limboto kabupaten Gorontalo dimana di lingkungan setempat banyak anak-anak yang putus sekolah dan mengkonsumsi alkohol; (c) Banyak siswa yang berasal dari panti asuhan yang keadaan ekonominya kurang baik; (d) Faktor kekurangan dalam bidang ekonomi menyebabkan anak setelah pulang sekolah menjadi buruh di pasar. Adapun solusi penyelesaiannya adalah dengan melakukan sosialisasi pentingnya membangun nilai-nilai demokrasi melalui pendidikan Kewarganegaraan. Metode yang digunakan dalam kegiatan pengabdian ini adalah dengan melakukan sosialisasi/penyuluhan kepada siswa SMP Negeri 2 limboto. Hasil yang dicapai menumbuhkan nilainilai demokrasi pada diri siswa, hal ini dapat dilihat dari perubahan sikap siswa yaitu menjadi lebih perhatian pada saat guru sedang menjelaskan materi pelajaran, banyak yang bertanya ketika guru membuka kesempatan untuk bertanya keadaan kelas menjadi lebih hidup dengan berbagai pendapat dari siswa dan tidak membosankan, berpikir kritis, lebih disiplin.
\end{abstract}

Kata kunci : nilai-nilai demokrasi, PKn, pengabdian masyarakat

\section{Abstract}

The value of democracy in students is the behavior of tolerance, respecting disagreements and knowing the diversity in the school environment. The lack of attitudes and behaviors of democratic values in SMP N 2 Limboto students is caused by several factors, namely: (a) lack of attention from the family environment to the child's learning process at home; (b) Most of the children's neighborhoods are located on the outskirts of Lake Limboto, Gorontalo district, where many children drop out of school and consume alcohol; (c) Many students come from orphanages whose economic conditions are not good; (d) Lack of economic factors causes children after school to become laborers in the market. The solution is to socialize the importance of building democratic values through civic education. The method used in this service activity is to do socialization/counseling to students of SMP Negeri 2 Limboto. The results achieved foster democratic values in students, this can be seen from the change in student attitudes, namely being more attentive when the teacher is explaining the subject matter, many ask when the teacher opens the opportunity to ask questions about the condition of the class becoming more lively with various opinions from students and not boring, critical thinking, more disciplined.

Keywords: democratic values, civics, community service

Copyright (c) 2021 Lucyane Djaafar, Roni Lukum, Zulfikar Adjie, Refandi Damopolii, Sintia Wantu, Siti Ramiati Alim

$\triangle$ Corresponding author

Address : Universitas Negeri Gorontalo

ISSN 2721-9224 (Media Cetak)

Email : lucyane.djaafar@gmail.com

ISSN 2721- 9216 (Media Online)

DOI : https://doi.org/10.31004/abdidas.v2i6.471 
1312 Membangun Nilai-nilai Demokrasi Melalui Pendidikan Kewarganegaraan di SMP Negeri 2 Limboto Kabupaten Gorontalo - Lucyane Djaafar, Roni Lukum, Zulfikar Adjie, Refandi Damopolii, Sintia Wantu, Siti Ramiati Alim

DOI: https://doi.org/10.31004/abdidas.v2i6.471

\section{PENDAHULUAN}

Pendidikan ialah suatu tindakan dalam memajukan kemampuan yang terdapat pada diri setiap manusia dan bertujuan untuk menjadikan manusia dewasa yang memiliki sumber daya manusia yang baik dan berkualitas. Undangundang sudah mengamanatkan agar pendidikan dapat mampu mengarahkan siswa menjadi warga negara yang demokratis. Untuk menjadi warga negara demokrasi diperlukan adanya pendidikan Kewarganegaraan. Menurut teorinya (Hasan, 2006) pola pembelajaran mata pelajaran PKn menekankan pada unsur pendidikan dan pembekalan pada siswa. Penekanan pembelajarannya bukan sebatas pada upaya menjelajahi siswa dengan sejumlah konsep yang bersifat hafalan belaka, melainkan terletak pada upaya agar siswa mampu menjadikan apa yang telah dipelajarinya sebagai bekal dalam memahami dan ikut serta dalam melakoni kehidupan masyarakat lingkungannya.

Oleh sebab itu, mata pelajaran PKn disetiap lembaga pendidikan harus dilakukan terus menerus dan berkesinambungan, serta melalui mata pelajaran PKn dapat membelajarkan siswa untuk lebih mengenal nilai-nilai demokrasi. Dengan demikian siswa dapat termotivasi dalam ikut serta demokrasi yang ada di lingkungan sekolah.

Pendidikan demokrasi membimbing peserta didik agar semakin dewasa dalam berdemokrasi dengan cara mensosialisasikan nilai-nilai demokrasi agar supaya perilaku peserta didik mencerminkan kehidupan demokrasi. Membangun pribadi yang demokratis merupakan salah satu fungsi pendidikan nasional seperti yang tercantum dalam pasal 3 UU Nomor 20 Tahun 2003 tentang Sisdiknas.

Mengembangkan nilai-nilai demokratis di Sekolah sangat penting dalam menghadapi era globalisasi yang saat ini dipercayai akan menampilkan banyak pergantian global seiring dengan percepatan keluar masuknya berbagai kultur dan peradaban baru dari berbagai bangsa di dunia. Itu artinya, dunia pendidikan dalam menghasilkan sumberdaya manusia yang bermutu dan profesional harus mempersiapakn generasi yang demokratis, sehingga memiliki resistence yang kokoh ditengah-tengah konflik peradaban. Langkah konkret yang menarik untuk direalisasi bersama, terutama oleh insan pendidik dan pihak-pihak yang berkecimpung di dunia pendidikan, adalah menciptakan ruang hidup dan praktek pendidikan sebagai sebuah kehidupan yang nyata (Rosyada, 2007).

Masalah yang terjadi pada siswa-siswa di SMP Negeri 2 Limboto ialah kurangnya pemahaman siswa dalam menumbuhkan nilai-nilai demokrasi sehingga sikap dan prilaku yang menjunjung nilai-nilai demokrasi sangat jarang mewarnai kegiatan siswa sehari-hari, hal ini terlihat dari kurangnya keberanian para siswa dalam mengungkapkan pendapatnya, kurang toleransi, tidak kreatif, tidak mampu berpikir kritis. Demikian pula pada saat pembelajaran respon siswa sangat kurang, mereka lebih banyak diam daripada menjawab pertanyaan-pertanyaan guru tentang materi yang diajarkan. penerimaan materi tidak dilakukan oleh siswa. 
1313 Membangun Nilai-nilai Demokrasi Melalui Pendidikan Kewarganegaraan di SMP Negeri 2 Limboto Kabupaten Gorontalo - Lucyane Djaafar, Roni Lukum, Zulfikar Adjie, Refandi Damopolii, Sintia Wantu, Siti Ramiati Alim

DOI: https://doi.org/10.31004/abdidas.v2i6.471

Pengabdian masyarakat ini dilaksanakan untuk bertujuan menyelesaikan masalah yang ada pada siswa di SMP Negeri 2 Limboto Kabupaten Gorontalo dalam menanamkan Nilai-nilai Demokrasi, dengan memberikan pendidikan demokrasi kepada siswa (peserta didik) untuk meraih pengetahuan, keterampilan, sikap, dan nilai-nilai yang berhubungan dengan berbudaya demokratis (Naval, 2002).

\section{METODE}

Pada kegiatan pengabdian kaloboratif antara Dosen dan Mahasiswa ini ialah dengan cara sosialisasi pada siswa-siswi yang berada di SMP Negeri 1 Limboto terkait penjelasan tentang contoh-contoh sikap membangun nilai-nilai demokrasi. Dalam kegiatan sosialisasi inipun kami dapat mengenali ruang lingkup masalah mengenai kurangnya pemahaman siswa terhadap nilai-nilai demokrasi. Dalam pelaksanaan kegiatan ini, Dosen dan Mahasiswa Prodi PPKn-UNG bekerja sama dengan pihak SMP Negeri 2 Limboto Kabupaten Gorontalo dalam menanamkan serta memberikan penguatan terhadap siswa dalam menumbuhkan nilai-nilai demokrasi melalui mata pelajaran Pendidikan Kewarganegaraan.

\section{HASIL DAN PEMBAHASAN}

Pada umumnya, pelaksanaan kegiatan pengabdian kaloboratif antara dosen dan mahasiswa ini tentang bagaimana menumbuhkan nilai-nilai demokrasi melalui pendidikan kewarganegaraan ini dilakukan, sebab, masih kurangnya pemahaman siswa terhaap nilai-nilai demokrasi.
Berangkat dari permasalahan yang terjadi pada siswa SMP Negeri 2 Limboto yakni kurangnya pemahaman dalam memehami nilainilai demokrasi melalui mata pelajaran PKn maka dengan ini Dosen dan Mahasiswa serta melibatkan pihak sekolah untuk melaksanakan kegiatan sosialisasi ini kepada siswa, agar nanti siswa-siswi yang berada di SMP Negeri 2 Limboto dapat memahami dan dapat menumbuhkan nilai-nilai demokarsi melalui mata pelajaran PKn.

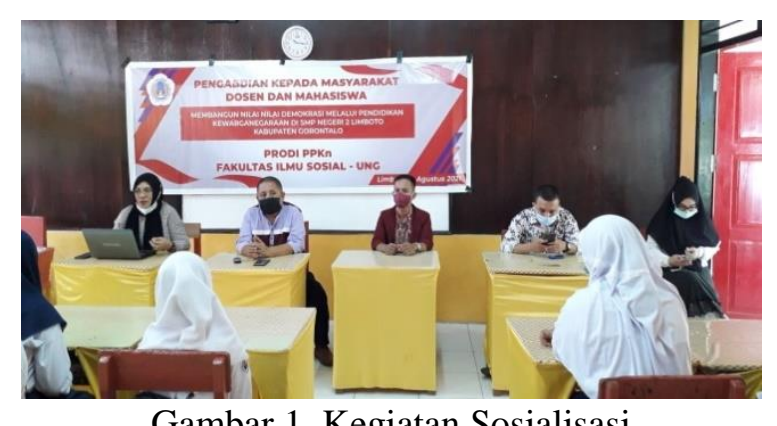

Kegiatan Sosialisasi ini dilaksanakan pada hari Jumat, 27 Agustus 2021 bertempat di SMP Negeri 2 Limboto Kabupaten Gorontalo, serta dihadiri oleh Akademisi UNG Sebagai Narasumber, Kepala Sekolah Guru PKn, Mahasiswa dan Siswa sebagai peserta dalam kegiatan sosialisasi.

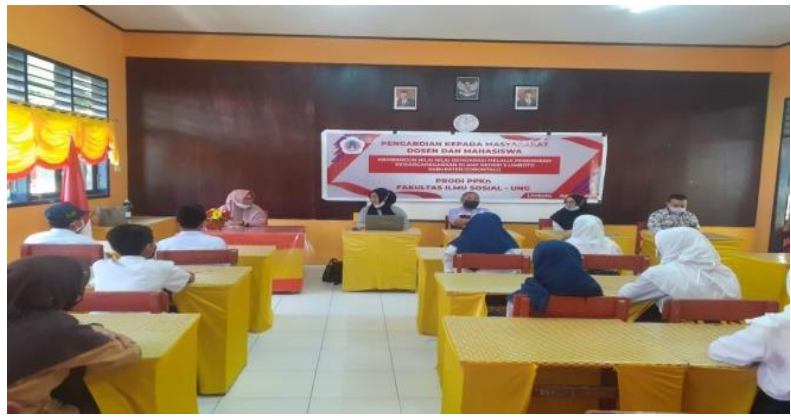

Gambar 2. Peserta Sosialisasi 
1314 Membangun Nilai-nilai Demokrasi Melalui Pendidikan Kewarganegaraan di SMP Negeri 2 Limboto Kabupaten Gorontalo - Lucyane Djaafar, Roni Lukum, Zulfikar Adjie, Refandi Damopolii, Sintia Wantu, Siti Ramiati Alim

DOI: https://doi.org/10.31004/abdidas.v2i6.471

Hasil dari kegiatan pengabdian pada masyarakat tentang menanamkan atau menumbuhkan nilai-nilai demokrasi melalui mata pelajaran Pendidikan Kewarganegaraan (PKn) bagi siswa-siswa di SMP Negeri 2 Limboto Kabupaten Gorontalo menghasilkan bagaimana memberikan penjelasan mengenai pengetahuan serta pemahaman kepada siswa betapa pentingnya membangun nilai-nilai demokrasi dalam proses pembelajaran seperti tertib dalam menaati peraturan sekolah, berani mengemukakan pendapat, bersikap menghargai perbedaan pendapat teman, aktif dalam kegiatan organisasi dan kegiatan ekstrakurikuler di sekolah, sikap empati kepada teman, pengendalian diri, sikap menghargai perbedaan agama, sikap menghargai perbedaan status sosial, sikap menghargai perbedaan, suku dan budaya serta hak dan kewajiban yang melekat pada diri manusia.

Setelah kegiatan pengabdian masyarakat di SMP Negeri 2 Limboto ini dilakukan, maka SMP Negeri 2 Limboto Kabupaten Gorontalo khususnya dalam menanamkan nilai-nilai demokrasi pada mata pelajaran Pendidikan Kewarganegaraan terhadap siswa-siswi dapat mengefektifkan peran dari sekolah dalam penyelenggarakan setiap pesta demokrasi dengan baik dilingkungan sekolah contohnya pada pemilihan ketua osis.

\section{SIMPULAN}

Berdasarkan pelaksanaan dari kegiatan pengabdian yang dilaksanakan di SMP Negeri 2 Limboto kabupaten Gorontalo dapat disimpulkan bahwa sosialisasi tentang membangun nilai-nilai demokrasi melalui pendidikan Kewarganegaraan Di SMP Negeri 2 Limboto Kabupaten Gorontalo" terlaksanakan dengan lancar dan sesuai dengan harapan yang diharapkan. Dosen dan mahasiswa Program Studi Pendidikan Pancasila dan Kewarganegaraan Jurusan IHK Fakultas Ilmu Sosial UNG dan Sekolah Menengah Pertama Negeri 2 Limboto Kabupaten Gorontalo serta para siswa yang hadir sebagai peserta dari kegiatan sosialisasi tersebut, turut berkontribusi dan berperan penting pada pelaksanaan kegiatan sosialisasi ini. Kegiatan sosialisasi ini dilakanakan karena masih kurangnya nilai-nilai berdemokrasi pada siswa SMP Negeri 2 Limboto, maka dari itu TIM Pengabdian Kaloboratif melaksanakan kegiatan tersebut.

\section{UCAPAN TERIMAH KASIH}

Dalam pelaksanaan kegiatan pengabdian kaloboratif antara dosen dan mahasiswa yang dilaksanakan di SMPN 2 Limboto, tidak lepas dari dukungan dan bantuan dari berbagai pihak terkait. Sehingga kami selaku TIM Pengabdian mengucapkan terimah kasih Kepada LP2M UNG, Fakultas Ilmu Sosial, Jurusan PPKn/IHK, SMP Negeri 2 Limboto, serta para siswa-siswi yang hadir sebagai peserta sosialisasi, sehingga kegiatan ini dapat berjalan dengan lancar.

\section{DAFTAR PUSTAKA}

Hasan, S. H. (2006). Pengembangan Model Pembelajaran PKn. Jakarta : Bumi Aksara.

Naval, C., \& Print Muirray \& Veldhuis, R. (2002). Education For Democratic Citizenship in the 
1315 Membangun Nilai-nilai Demokrasi Melalui Pendidikan Kewarganegaraan di SMP Negeri 2 Limboto Kabupaten Gorontalo - Lucyane Djaafar, Roni Lukum, Zulfikar Adjie, Refandi Damopolii, Sintia Wantu, Siti Ramiati Alim

DOI: https://doi.org/10.31004/abdidas.v2i6.471

New Europe: Context and Reform. European

Journal Of Education.

Rosyada, D. (2007). Paradigma Pendidikan

Demokrasi : Sebuah Model Pelibatan

Masyarakat dalam Penyelenggaraan

Pendidikan . Jakarta: Kencana Prenada Media

Group.

Undang-Undang Nomor 20 Tahun 2003 tentang Sisdiknas 